\title{
The Only Chemoreceptor Encoded by che Operon Affects the Chemotactic Response of Agrobacterium to Various Chemoeffectors
}

\author{
Jingyang Ye, Miaomiao Gao, Qingxuan Zhou, Hao Wang, Nan Xu and Minliang Guo *D \\ College of Bioscience and Biotechnology, Yangzhou University, Yangzhou 225009, China; \\ DX120170118@yzu.edu.cn (J.Y.); miaomiaogao1@163.com (M.G.); m18362821722@163.com (Q.Z.); \\ wanghao@yzu.edu.cn (H.W.); nanxu@yzu.edu.cn (N.X.) \\ * Correspondence: guoml@yzu.edu.cn; Tel.: +86-0514-87962283; Fax: +86-0514-87991747
}

Citation: Ye, J.; Gao, M.; Zhou, Q.; Wang, H.; Xu, N.; Guo, M. The Only Chemoreceptor Encoded by che Operon Affects the Chemotactic Response of Agrobacterium to Various Chemoeffectors. Microorganisms 2021, 9, 1923. https://doi.org/10.3390/ microorganisms 9091923

Academic Editor: Toni A. Chapman

Received: 12 August 2021

Accepted: 7 September 2021

Published: 10 September 2021

Publisher's Note: MDPI stays neutral with regard to jurisdictional claims in published maps and institutional affiliations.

Copyright: (C) 2021 by the authors Licensee MDPI, Basel, Switzerland. This article is an open access article distributed under the terms and conditions of the Creative Commons Attribution (CC BY) license (https:// creativecommons.org/licenses/by/ $4.0 /)$.

\begin{abstract}
Chemoreceptor (also called methyl-accepting chemotaxis protein, $\mathrm{MCP}$ ) is the leading signal protein in the chemotaxis signaling pathway. MCP senses and binds chemoeffectors, specifically, and transmits the sensed signal to downstream proteins of the chemotaxis signaling system. The genome of Agrobacterium fabrum (previously, tumefaciens) C58 predicts that a total of 20 genes can encode MCP, but only the MCP-encoding gene atu0514 is located inside the che operon. Hence, the identification of the exact function of atu0514-encoding chemoreceptor (here, named as $\mathrm{MCP}_{514}$ ) will be very important for us to understand more deeply the chemotaxis signal transduction mechanism of A. fabrum. The deletion of atu0514 significantly decreased the chemotactic migration of A. fabrum in a swim plate. The test of atu0514-deletion mutant $(\Delta 514)$ chemotaxis toward single chemicals showed that the deficiency of $\mathrm{MCP}_{514}$ significantly weakened the chemotactic response of A. fabrum to four various chemicals, sucrose, valine, citric acid and acetosyringone (AS), but did not completely abolish the chemotactic response. $\mathrm{MCP}_{514}$ was localized at cell poles although it lacks a transmembrane (TM) region and is predicted to be a cytoplasmic chemoreceptor. The replacement of residue Phe328 showed that the helical structure in the hairpin subdomain of $\mathrm{MCP}_{514}$ is a direct determinant for the cellular localization of $\mathrm{MCP}_{514}$. Single respective replacements of key residues indicated that residues Asn336 and Val353 play a key role in maintaining the chemotactic function of $\mathrm{MCP}_{514}$.
\end{abstract}

Keywords: Agrobacterium fabrum; chemotaxis; chemoreceptor; cellular localization; methyl-accepting chemotaxis protein; chemoeffector

\section{Introduction}

Chemotaxis is an adaptive behavior of motile bacteria moving along the concentration gradient of chemoeffectors towards an optimal environment [1,2]. This adaptive behavior is regulated by a two-component system composed of histidine kinase CheA and chemotaxis response regulator protein CheY $[3,4]$. When a chemical attractant exists in the environment, methyl-accepting chemotaxis protein (MCP) can bind the attractant, and the ligand binding will change the conformation of MCP; then, through a coupling protein CheW, the kinase activity of CheA will be suppressed. The suppression of CheA activity will delay the transfer of the phosphoryl group to the response regulator protein CheY, resulting in the decrease in phosphorylated CheY $[5,6]$. The absence of phosphorylated CheY makes less change of the rotational direction of flagella and thus keeps bacteria swimming to the attractant. On the contrary, when the concentration of attractant goes down (or repellent goes up), MCP activates the kinase activity of CheA. Self-phosphorylated CheA passes the phosphoryl groups to CheY. Phosphorylated CheY will bind to the flagellar motor and change the rotational direction of flagella frequently, which causes cell tumbling and changes direction away from the adverse environment $[7,8]$.

Many bacteria possess chemotactic behavior for a large number of chemicals, such as different nitrogen or carbon nutrient substances, different environmental pollutants, or different signal chemicals released by their ecological partners [9-13]. To sense the vast 
chemoeffectors, bacteria must evolve an enormous number of different chemoreceptors. A typical chemoreceptor contains an N-terminal periplasmic ligand binding domain (LBD), a transmembrane (TM) helical region, a HAMP (existing in histidine kinases, adenylate cyclases, methyl-accepting chemotaxis proteins, and phosphatases) domain, and a C-terminal cytoplasmic signaling domain (SD), comprising a methyl-accepting (MA) subdomain, a flexible bundle (FB) subdomain, and a hairpin (HP) subdomain (Figure 1A) $[7,14,15]$. The hairpin subdomain interacts with the coupling protein $\mathrm{CheW}$ and the senor kinase CheA. Chemoreceptors use LBD to recognize chemoeffectors. In order to recognize different chemicals, chemoreceptors have evolved many different types of LBDs [9]. According to the LBD and membrane topology, chemoreceptors can be divided into four classes, of which class IV is cytoplasmic (soluble) chemoreceptors and the rest are transmembrane chemoreceptors. Based on the length from the N-terminus to the MA domain, cytoplasmic chemoreceptors can be divided into two subclasses of IVa and IVb. The N-terminal domain of IVa has at least 108 amino acids, while the N-terminal domain of IVb is shorter than 108 amino acids [16,17]. Among 8384 chemoreceptors defined by the MA subdomain in the complete genome of the SMART database [18], 14\% of the chemoreceptors are cytoplasmic chemoreceptors. The ligand-binding motif is generally predicted at the N-terminal of IVa subclass chemoreceptors. Based on the statistical analysis of 1129 chemoreceptors with LBD in the SMART database, $47 \%$ of LBD is PAS domain, such as AerC in A. brasilense [19]; CZB domain found in Helicobacter pylori TlpD [20], is the second most common LBD, accounting for $8 \%$ of all IVa chemoreceptors; protoglobin [21] is the third most common LBD, accounting for $7 \%$ of all IVa chemoreceptors; the remaining domains account for less than $1 \%$ [22].

Agrobacterium fabrum is a Gram-negative bacterium and induces crown gall tumor disease in most dicotyledonous plants by genetically transforming the host $[23,24]$. In the natural environment, $A$. fabrum is usually distributed around the rhizosphere of a plant, and chemotaxis is an important first process of its interaction with the host. It has two kinds of lifestyles; one is to survive in the soil environment independently and the other is symbiotic with the plant as a pathogen [25-27]. Only when it recognizes and senses the sugars, acidic $\mathrm{pH}$ or phenols released by the host can $A$. fabrum begin the infecting process by chemotaxis toward the wound site of the host [28]. In the late 1980s, chemotaxis of A. fabrum was preliminarily studied, proving that it can respond to sugars, amino acids and phenols released by the injured plant tissues [29-31], but the specific chemotaxis mechanism has been rarely studied [32]. The genome sequence of $A$. fabrum $\mathrm{C} 58$ predicts that it has only one chemotaxis gene cluster (che cluster). The gene organization of this gene cluster is shown in Figure 1B. This gene cluster contains the genes encoding most components of the chemotaxis system. Spaces between the adjacent genes are very short and some adjacent genes even share a few nucleotides. All the genes in this cluster are predicted to be controlled by the same upstream promoter and thus located on the same operon [12,33]. In addition to the atu0514 gene, the only gene annotated to encode MCP in this che operon, A. fabrum carries an additional 19 MCP-encoding genes, including 1 on the Ti plasmid, 1 on the At plasmid, 5 on the linear chromosome, and the remaining 12 on the circular chromosome [33]. The number of MCPs in A. fabrum C58 indicates its complex chemotaxis signal and strong environmental adaptability [34].

The A. fabrum atu0514 gene, located on the circular chromosome, is the only MCPencoding gene in the che operon [12]. Unlike all other MCPs, $\mathrm{MCP}_{514}$ is co-expressed with all other core chemotaxis components. Therefore, it may be the most important chemoreceptor, and characterizing its function is very helpful for us to further understand the chemotaxis signal transduction mechanism of $A$. fabrum. In this study, we firstly constructed the atu0514-deletion mutant $\Delta 514$ and the complemented strain $\Delta 514-C$ and tested the effect of atu0514-deficiency on the chemotactic response of A. fabrum C58. We also identified the key residues that affect the cellular localization and function of $\mathrm{MCP}_{514}$. 


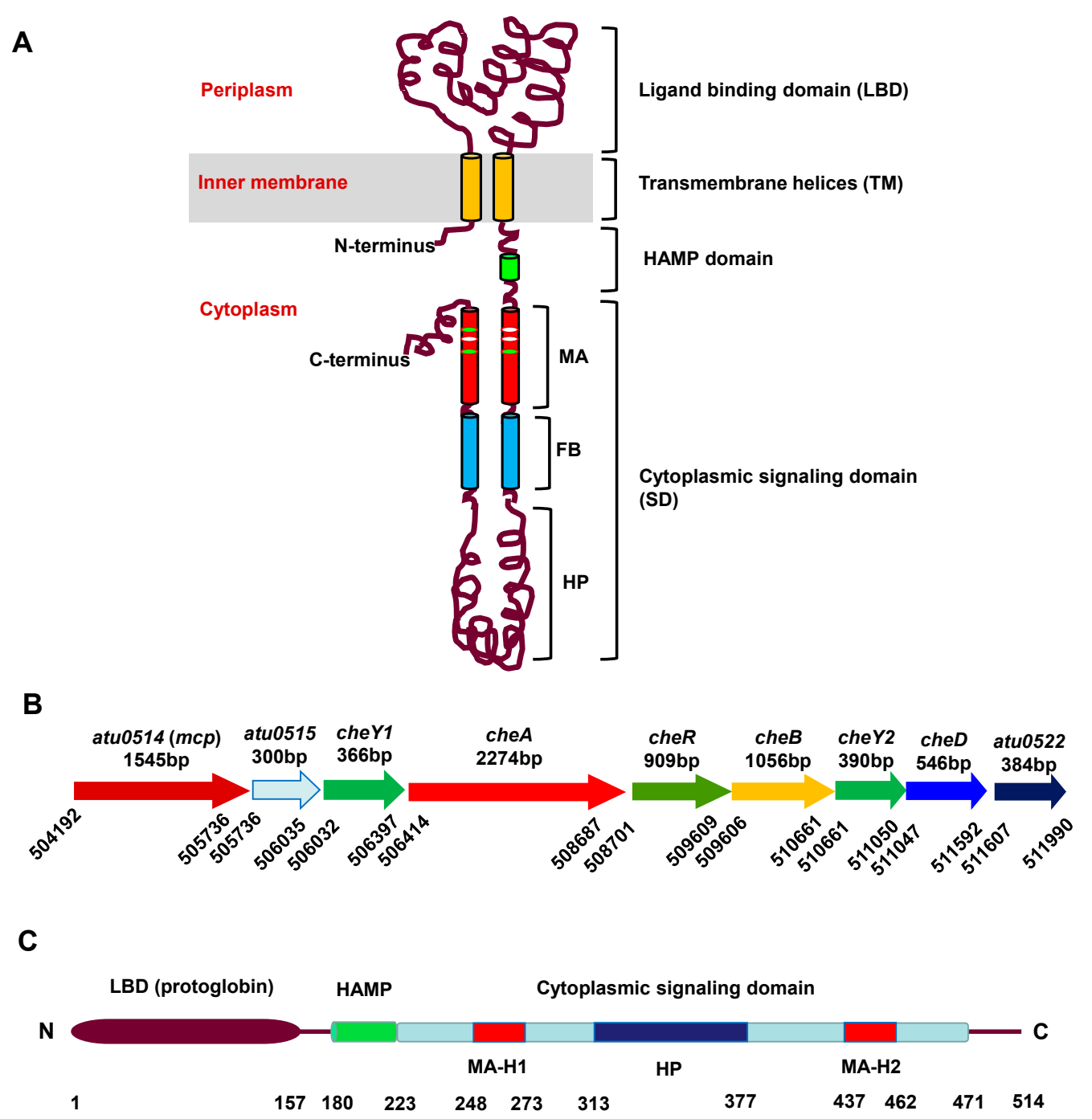

Figure 1. Topological structure of a typical MCP, gene organization of a A. fabrum che gene cluster and domain organization of $\mathrm{MCP}_{514}$. (A) Architectural model of a typical MCP. Cylinders represent $\alpha$-helices. MA: methyl-accepting (or sensory adaptation) subdomain; FB: flexible bundle subdomain; HP: hairpin subdomain. (B) Gene organization of $A$. fabrum che gene cluster. Arrows represent genes. Above the arrows are the names and lengths of the genes. Numbers under the arrows indicate the nucleotide position of the gene border. (C) Predicted domain organization of $\mathrm{MCP}_{514}$. MA-H1: $\alpha$-helix 1 of MA subdomain; MA-H2: $\alpha$-helix 2 of MA subdomain; numbers under the domains indicate the amino acid position of the domain border.

\section{Materials and Methods}

\subsection{Primers, Plasmids, Bacterial Strains and Growth Conditions}

The primers, plasmids and bacterial strains used in this study are listed in Supplementary Tables S1 and S2. Lysogeny broth (LB) liquid or agar medium was used to grow $E$. coli at $37^{\circ} \mathrm{C}$ [35]. A. fabrum was grown in MG/L or AB-sucrose liquid or agar medium at $28^{\circ} \mathrm{C}[36,37]$. Concentrations of ampicillin and kanamycin used for E. coli were 100 and $50 \mu \mathrm{g} / \mathrm{mL}$, respectively. Concentrations of kanamycin and carbenicillin for A. fabrum were $100 \mu \mathrm{g} / \mathrm{mL}$.

\subsection{DNA Manipulations}

DNA manipulations followed the standard molecular protocols [35]. Plasmid isolation was performed with the TIANprep Mini Plasmids Kit (TIANGEN BIOTECH Corporation, Beijing, China). PCR products obtained by Veriti 96-well cycler (Thermo Fisher Scientific Inc., Waltham, MA USA) and DNA fragments were purified from agarose gels by using 
the TaKaRa MiniBEST Agarose Gel DNA Extraction Kit (TaKaRa Corporation, Dalian, China). Plasmids were transferred into $E$. coli competent cells by heat-shock [35] and into $A$. fabrum by the Eppendorf electroporation instrument Eporator ${ }^{\circledR}$ (Eppendorf AG, Hamburg, Germany) [36].

\subsection{Mutagenesis and Complementation of Atu0514}

Based on the principle of homologous recombination, we used the pEX18Km-derived gene replacement plasmids to construct the corresponding gene deletion mutants [38,39]. Plasmid pEX18Km carries both a positive selection marker (kanamycin resistance, $\mathrm{K}_{\mathrm{m}}{ }^{\mathrm{R}}$ ) and counterselectable marker (suicide gene $s a c \mathrm{~B}$ ) and cannot be replicated in A. fabrum. The positive selection marker allowed to select the transformants, in which the whole plasmid was integrated into the genome by the first homologous recombination. The counterselectable marker allowed to counterselect the transformants, in which both the target DNA fragment and the undesirable plasmid backbone were deleted from the genome by the second homologous recombination. The combined utilization of selectable and counterselectable markers can precisely generate an unmarked mutant without any undesirable DNA fragment (Figure S1A). A. fabrum wild type C58 was used to construct the atu0514deletion mutant $\Delta 514$. A. fabrum cheW $_{1}-$ cheW $_{2}$ double-deletion mutant $\Delta \mathrm{w}[40$ ] was used to construct atu0514-cheW -cheW $_{2}$ triple-deletion mutant $\Delta 514 \Delta \mathrm{w}$. The desirable mutant was screened using PCR (Figure S1B) and verified by sequencing. The DNA fragment encoding amino acids $14-453$ of $\mathrm{MCP}_{514}$ was precisely deleted in both $\Delta 514$ and $\Delta 514 \Delta \mathrm{w}$ mutants (Figure S1C). The complementation of $\mathrm{MCP}_{514}$ in the atu0514-deletion mutant was fulfilled by the introduction of plasmid expressing $\mathrm{MCP}_{514}$ (or its variants). Gene fusions with the egfp as well as deletion constructs were created by overlap extension PCR, as described by Higuchi [41]. These egfp-fused genes were cloned into the modified vector pUCA19 to generate the plasmids expressing eGFP-fused proteins. When these eGFP-fused proteins were expressed in A. fabrum cells, the cellular localizations of these eGFP-fused proteins could be observed by using Zeiss confocal microscope LSM 880 NLO (Carl Zeiss AG, Oberkochen, Germany).

\subsection{Chemotaxis Assays}

The procedure of capillary assay was followed as described by Adler in 1973 [42], with minor modifications. A. fabrum cells were harvested from mid-log-phase culture by centrifugation at $4000 \mathrm{rpm}$ for $3 \mathrm{~min}$ at room temperature $\left(25^{\circ} \mathrm{C}\right)$ and suspended in chemotaxis buffer $\left(0.1 \mathrm{mmol} / \mathrm{L}\right.$ EDTA, $\left.10 \mathrm{mmol} / \mathrm{L} \mathrm{KH}_{2} \mathrm{PO}_{4}, \mathrm{pH} 7.0\right)$ to an $\mathrm{OD}_{600 \mathrm{~nm}}$ of 0.1 . A. fabrum cell suspension $(300 \mu \mathrm{L})$ was used to make a bacterial pond. The capillary tube was sealed at one end and filled with attractant at peak concentration dissolved in the chemotaxis buffer. The open end of the capillary tube was inserted into the bacterial pond and incubated for $1 \mathrm{~h}$ at room temperature $\left(25^{\circ} \mathrm{C}\right)$, then, the solution in the capillary tube was expelled and completely transferred into $1 \mathrm{~mL}$ of $\mathrm{AB}$-sucrose medium. Dilutions were plated in duplicate on MG/L plates and incubated for 2 days at $28^{\circ} \mathrm{C}$. The colonies in the plates were counted and represented the number of cells attracted to the capillary tube.

The procedure of swim agar plate assay was followed that described by Merritt [43], with minor modifications. The tested strains were inoculated in AB-sucrose liquid medium and grown to the middle log phase, and then, the $\mathrm{OD}_{600 \mathrm{~nm}}$ was adjusted to 0.6 by using AB-sucrose liquid medium. A total of $3 \mu \mathrm{L}$ of bacterial suspension was dropped onto an $\mathrm{AB}$-sucrose swim plate containing $0.2 \%$ agar, and 5 replicates were set. After incubation at $28{ }^{\circ} \mathrm{C}$ for $36-48 \mathrm{~h}$, the diameter of the bacterial colony circle was measured, and the data were statistically analyzed.

\subsection{Bacterial Two-Hybrid Analyses}

The bacterial two-hybrid system from the Stratagene ${ }^{\circledR}$ (Agilent Technologies Inc., Santa Clara, CA, USA) was used for testing protein-protein interactions. All the operations were conducted according to the manual. The open read frame (ORF) of atu0514 was 
inserted into the bait plasmid pBT to express $\lambda \mathrm{cI}-\mathrm{MCP}_{514}$ (bait) fusion protein. ORFs of $c \mathrm{CW}_{1}$ and $c h e \mathrm{~W}_{2}$ were inserted to the target plasmid pTRG to express $\mathrm{CheW}_{1}$ (target)RNAP and $\mathrm{CheW}_{2}$ (target)-RNAP fusion proteins, respectively. The interaction between bait $\left(\mathrm{MCP}_{514}\right)$ and target $\left(\mathrm{CheW}_{1}\right.$ or $\left.\mathrm{CheW}_{2}\right)$ will take $\lambda \mathrm{cI}$ and RNAP together to induce the expression of $\beta$-galactosidase, and thus, the bacterial colonies growing on plates containing $80 \mu \mathrm{g} / \mathrm{mL}$ X-gal will be blue. Otherwise, the bacterial colonies will be of normal color. Galactosidase activity was determined by the method of Miller [44].

\subsection{Fluorescence Microscopy}

For microscopy observation, agrobacterial cells from the mid-log-phase cultures were added to the center of the slides. A coverslip was placed on top of the culture droplet. The edges of the coverslip were sealed with acrylic polymer to prevent drying. A. fabrum cells were visualized by a Zeiss LSM 880 NLO system (Carl Zeiss AG, Oberkochen, Germany) using an Ar laser (excitation wavelength of $488 \mathrm{~nm}$ and emission wavelength of 500 to $550 \mathrm{~nm})$ and a $\times 100$ oil immersion objective. The images were analyzed and edited using ZEN lite (Blue edition), version 3.2 (Carl Zeiss AG, Oberkochen, Germany).

\subsection{Statistical Analysis}

The quantitative data shown in this study were the means with the standard deviations (SDs), which were derived from at least three independent experiments conducted in triplicate. Differences among bacterial strains were compared using one-way analysis of variance (ANOVA), followed by the Tukey test for multiple comparisons. The statistical analysis was conducted using Microsoft Office Excel's data analysis tool (2019 version) (Microsoft Corporation, Redmond, WA, USA).

\section{Results}

\subsection{MCP 514 Is a Cytoplasmic Chemoreceptor, but Localized at Cell Poles}

By SMART analysis, $\mathrm{MCP}_{514}$ has a total of 514 amino acids and carries three conserved domains, protoglobin domain, HAMP domain and cytoplasmic signal domain (SD), in the order from N-terminal to C-terminal (Figure 1C). The protoglobin domain of $\mathrm{MCP}_{514}$ shares $13.51 \%$ sequence identity with the LBD of HEMAT, a cytoplasmic chemoreceptor from B. subtilis [21], through the SWISS-Model homology search. According to Alexandre's heptapeptide classification, cytoplasmic signal domain (SD) belongs to the $36 \mathrm{H}$ family [45]. The two best-studied MCPs of the $36 \mathrm{H}$ family are Tsr and Tar proteins of E. coli. Further analysis on the secondary structure of $\mathrm{MCP}_{514}$ by SOSUI [46] and SPLIT [47] shows that $\mathrm{MCP}_{514}$ does not contain the hydrophobic domain, indicating that $\mathrm{MCP}_{514}$ does not possess a transmembrane (TM) region and belongs to an IVa cytoplasmic chemoreceptor.

Transmembrane chemoreceptors are mainly localized at cell poles, but the cytoplasmic chemoreceptors have a wider cellular localization mode, ranging from co-localization with transmembrane chemoreceptor arrays to a diffuse cytoplasmic distribution [48]. The localization of some cytoplasmic chemoreceptors is associated with the physiology and life cycle of bacteria [22]. According to previous classification [9], $\mathrm{MCP}_{514}$ should be classified into the category of the cytoplasmic chemoreceptor due to the lack of a transmembrane region, but we do not know the cellular localization of $\mathrm{MCP}_{514}$. To observe the cellular localization of $\mathrm{MCP}_{514}$, the enhanced green fluorescent protein (eGFP) was fused to the Nterminus of $\mathrm{MCP}_{514}$ because only the N-terminally GFP-tagged $\mathrm{MCP}_{514}$ was functional [49]. This eGFP-MCP ${ }_{514}$ fusion protein was expressed in the $\mathrm{MCP}_{514}$-deficient strain $\Delta 514$. Figure $2 \mathrm{~A}$ showed that the eGFP-MCP ${ }_{514}$ fusion protein is localized at the poles of the $A$. fabrum cell. However, the eGFP-MCP ${ }_{514}$ fusion protein is distributed in the whole cell of E. coli (Figure $2 \mathrm{~B}$ ), verifying that $\mathrm{MCP}_{514}$ lacks a transmembrane domain. These data also imply that the polar localization of $\mathrm{MCP}_{514}$ in A. fabrum cell requires the assistance of other A. fabrum proteins. 

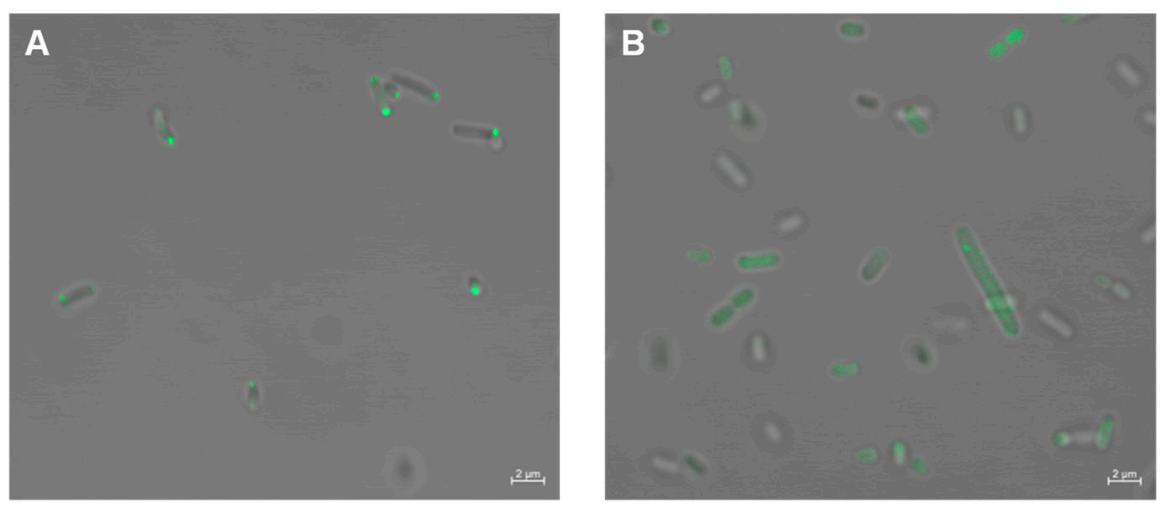

Figure 2. Cellular localization of $\mathrm{MCP}_{514}$. Plasmid expressing the eGFP-MCP 514 fusion protein was introduced into A. fabrum $\mathrm{MCP}_{514}$-deficient mutant $\Delta 514$ (A) and E. coli strain $\mathrm{DH} 5 \alpha(\mathbf{B})$, respectively. Bacterial cells were grown to middle-log phase and observed by using confocal laser-scanning microscopy.

\section{2. $\mathrm{MCP}_{514}$ Significantly Affects the Chemotactic Response of Agrobacterium Fabrum}

Since $\mathrm{MCP}_{514}$ is localized at cell poles, we next try to test the effect of $\mathrm{MCP}_{514}$ on the chemotactic response of A. fabrum. When bacterium grows on the swim agar plate, the utilization of nutrient substances by bacterium will result in a nutrient concentration gradient. Bacterium with chemotaxis will move outward along the nutrient concentration gradient and grow a big colony. Consequently, the overall chemotactic response to nutrient substances can be characterized by measuring the colony size in the swim agar plate [10]. A. fabrum has only one CheA, and CheA is the key component of a chemotaxis system. The deletion of the cheA gene will completely abolish the chemotactic response of $A$. fabrum, and thus, the CheA-deficient mutant $\Delta a$ was used as a control of chemotaxis deficiency [40]. As shown in Figure 3, the deficiency of $\mathrm{MCP}_{514}$ significantly attenuates the overall chemotactic response of $A$. fabrum to nutrient substances. The complementation of $\mathrm{MCP}_{514}$ by the introduction of $\mathrm{MCP}_{514}$-expressing plasmid can fully restore the chemotactic response of the $\mathrm{MCP}_{514}$-deficient mutant to the level of the wildtype, confirming the role of $\mathrm{MCP}_{514}$ in the chemotactic response. These results also provided evidence that the deletion of atu0514 did not have a polar effect on the rest of the che operon. Previous research showed that $A$. fabrum has chemotaxis toward sugars, amino acids, organic acids and phenols $[29,30]$. The traditional capillary assay is an effective method for quantifying the chemotaxis ability of bacteria [42]. The chemotactic responses of wildtype C58, mutant $\Delta 514$ and complemented strain $\Delta 514-\mathrm{C}$ to four various chemicals $(1 \mu \mathrm{mol} / \mathrm{L}$ sucrose, $1 \mathrm{mmol} / \mathrm{L}$ valine, $1 \mathrm{mmol} / \mathrm{L}$ citric acid and $0.1 \mu \mathrm{mol} / \mathrm{L}$ acetosyringone (AS)) were measured by using the traditional capillary method. As shown in Figure 4, the deletion of atu0514 significantly weakens the chemotaxis of A. fabrum toward these four different types of chemicals. However, the chemotaxis of strain $\Delta 514$ toward these chemicals does not completely disappear, indicating that $\mathrm{MCP}_{514}$ is not the receptor directly recognizing these substances but affects the chemotaxis efficiency in other ways.

3.3. Both $\mathrm{CheW}_{1}$ and $\mathrm{CheW}_{2}$ Interact with $\mathrm{MCP}_{514}$ but Do Not Affect the Cellular Localization of $M C P_{514}$

It is known that $\mathrm{CheW}$ couples CheA to chemoreceptors and forms stable ternary signaling complexes with chemoreceptors and CheA [3]. To confirm the role of $\mathrm{MCP}_{514}$ in the chemotaxis signal transduction pathway of $A$. fabrum, the bacterial two-hybrid system was used to test the interaction between $\mathrm{MCP}_{514}$ and two CheWs. As shown in Figure 5A, the colors of the colonies representing $\mathrm{MCP}_{514} / \mathrm{CheW}_{1}$ and $\mathrm{MCP}_{514} / \mathrm{CheW}_{2}$ interaction are bluer than that of the negative control. The quantification of $\beta$-galactosidase activity also showed that the $\beta$-galactosidase activities of the colonies expressing these two tested protein pairs $\left(\mathrm{MCP}_{514} / \mathrm{CheW}_{1}\right.$ and $\left.\mathrm{MCP}_{514} / \mathrm{CheW}_{2}\right)$ are significantly higher than that of 
the negative control (Figure 5B). This indicates that $\mathrm{MCP}_{514}$ protein interacted with both $\mathrm{CheW}_{1}$ and $\mathrm{CheW}_{2}$ proteins.
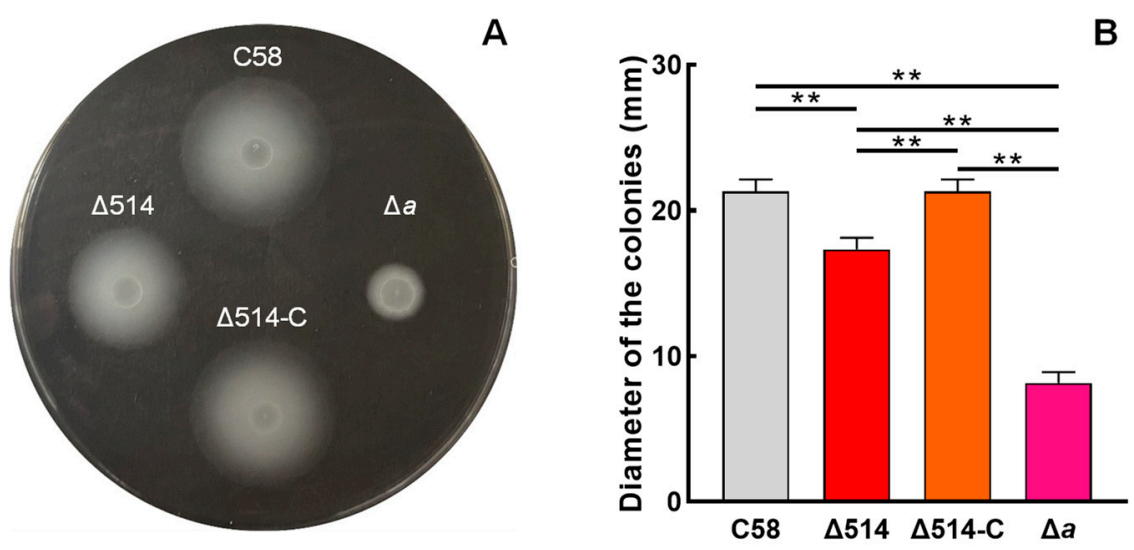

Figure 3. Effect of $\mathrm{MCP}_{514}$ deficiency on the chemotactic response of A. fabrum. The tested A. fabrum strains were grown to middle-log phase. Bacterial cells were collected and resuspended to the same $\mathrm{OD}_{600 \mathrm{~nm}}$ (0.6). Equal amounts of cells from these cell suspensions were inoculated on the swim plates. The plates were incubated at $28{ }^{\circ} \mathrm{C}$ for 2 days. (A) Typical colonies of these tested A. fabrum strains. (B) The swim-ring diameters of these tested A. fabrum strains on the swim plate. The data represent the means \pm SDs from five independent experiments in triplicate. The bars paired with two asterisks "**" represent that they are statistically different at $p<0.01$ via the one-way ANOVA, followed by Tukey test. C58, A. fabrum wildtype C58; $\Delta 514, \mathrm{MCP}_{514}$-deficient mutant; $\Delta 514-\mathrm{C}$, $\Delta 514$ mutant complemented with $\mathrm{MCP}_{514}$ through plasmid; $\triangle a$, CheA-deficient mutant (a control of chemotaxis deficiency).
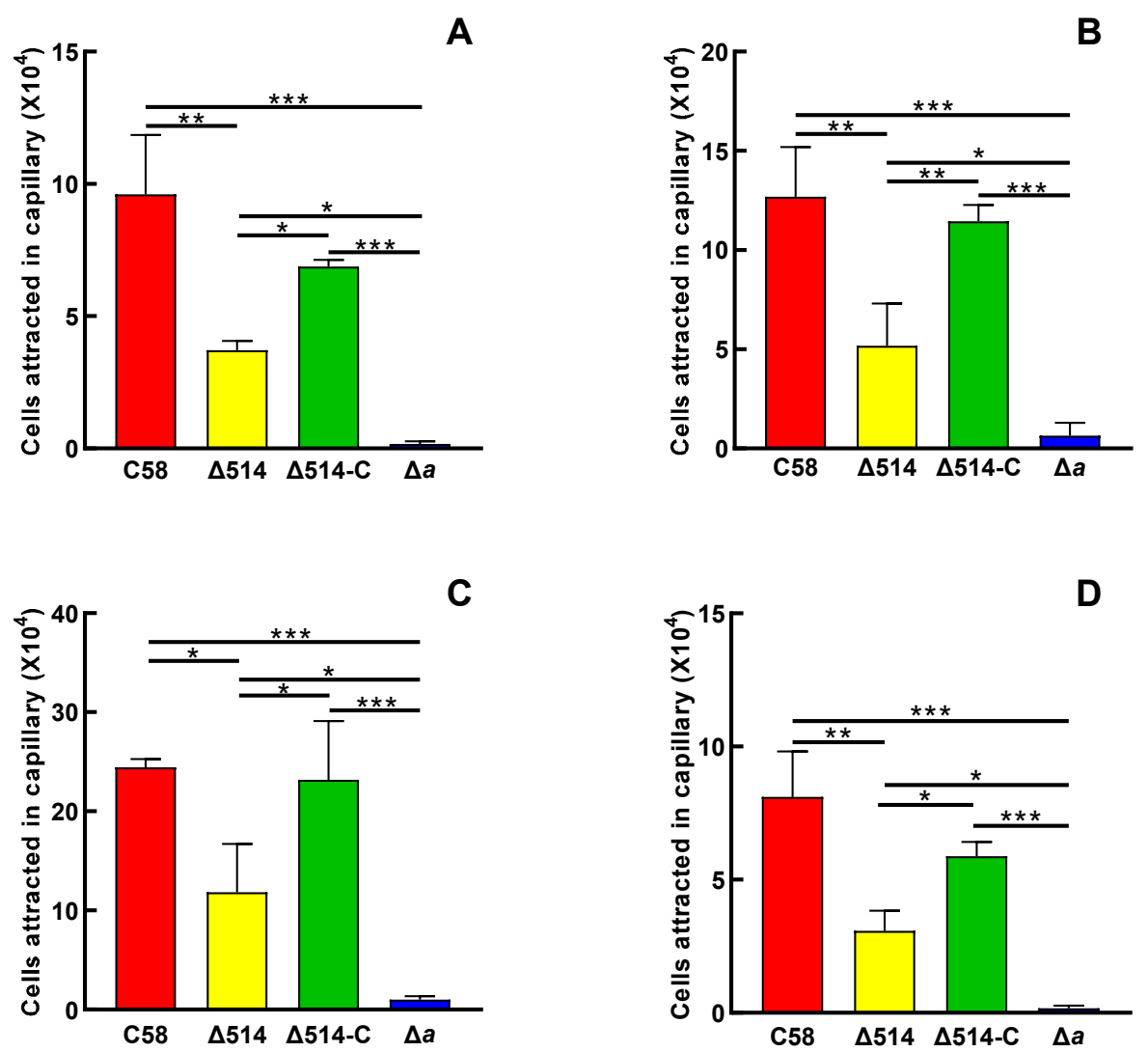

Figure 4. Effect of $\mathrm{MCP}_{514}$ deficiency on the chemotactic responses of A. fabrum to sucrose (A), valine 
(B), citric acid (C) and acetosyringone (D). A. fabrum cells in the middle-log phase were collected, washed and then adjusted to an $\mathrm{OD}_{600 \mathrm{~nm}}$ of 0.1 with chemotaxis buffer. Capillary tubes containing chemotaxis buffer with $10^{-6} \mathrm{~mol} / \mathrm{L}$ sucrose, $10^{-3} \mathrm{~mol} / \mathrm{L}$ valine, $10^{-3} \mathrm{~mol} / \mathrm{L}$ citric acid, or $10^{-7} \mathrm{~mol} / \mathrm{L}$ acetosyringone were inserted into the cell suspensions for $1 \mathrm{~h}$ at room temperature $\left(25^{\circ} \mathrm{C}\right)$. Cells migrating to the capillary tube were counted by using colony count. The attracted cells are equal to the cells in the capillary tube with attractant minus the cells in the capillary tube without attractant. The data represent the means \pm SDs from three independent experiments with triplicate. The bars paired with "**, “**” and "**** marks represent that they are different in a statistical manner at $p<0.05,0.01$ and 0.001, respectively, via the one-way ANOVA, followed by Tukey test. The strain names in the horizontal axis are the same as in Figure 3.

A

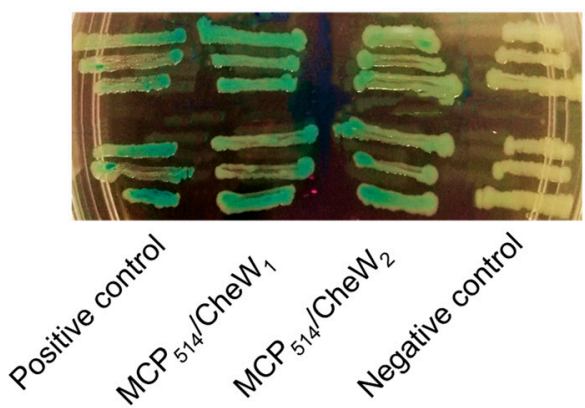

B

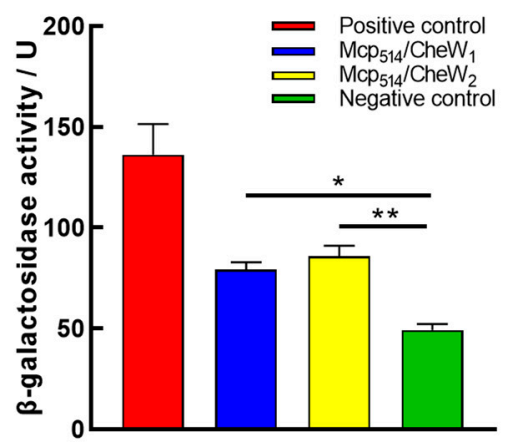

Figure 5. The interactions of $\mathrm{MCP}_{514}$ with two CheWs of $A$. fabrum. The interaction between $\mathrm{MCP}_{514}$ and $\mathrm{CheW}$ was tested by using a bacterial two-hybrid assay. All the operations followed the manual. The interaction between two tested proteins will induce the expression of $\beta$-galactosidase, and bacterial colonies will show blue color on the X-gal indicator plate. (A) Colony color on the X-gal indicator plate. (B) The activity of $\beta$-galactosidase reporter induced by the interacting proteins. Data are the means \pm SDs from three independent experiments with triplicate. The bars paired with "*" and "***" marks represent that they are different in a statistical manner at $p<0.05$ and 0.01 , respectively via the one-way ANOVA, followed by Tukey test. Positive control, interaction between two known proteins (LGF2 and Gal11 ${ }^{\mathrm{P}}$ ) provided by the manufacturer; $\mathrm{MCP}_{514} / \mathrm{CheW}_{1}$, interaction between $\mathrm{MCP}_{514}$ and $\mathrm{CheW}_{1} ; \mathrm{MCP}_{514} / \mathrm{CheW}_{2}$, interaction between $\mathrm{MCP}_{514}$ and $\mathrm{CheW}_{2}$; negative control, without any interacting proteins.

Both $\mathrm{CheW}_{1}$ and $\mathrm{CheW}_{2}$ interact with $\mathrm{MCP}_{514}$ and most of the ternary MCP-CheW$\mathrm{CheA}$ complexes are localized in the cell poles. However, $\mathrm{MCP}_{514}$ lacks a transmembrane domain. It is unknown whether the cellular localization of $\mathrm{MCP}_{514}$ is dependent on the ternary $\mathrm{MCP}-\mathrm{Ch}$-W-CheA complex. Therefore, we tested the effects of the $\mathrm{CheW}$ deficiency on the cellular localization of $\mathrm{MCP}_{514}$. To determine whether $\mathrm{CheW}$ affects the cellular localization of $\mathrm{MCP}_{514}$, a plasmid expressing eGFP- $\mathrm{MCP}_{514}$ fusion protein was transferred into the atu0514-cheW $1-c h e W_{2}$ triple deletion mutant $\Delta 514 \Delta w$. Fluorescence observation showed that $\mathrm{MCP}_{514}$ in the CheW-deficient strain is still localized at cell poles, indicating that $\mathrm{CheW}$ deficiency does not affect the polar localization of $\mathrm{MCP}_{514}$ (Figure 6).

\subsection{Helical Structure of Hairpin Subdomain Is Required for the Cellular Localization of MCP 514}

Due to the lack of a transmembrane domain in $\mathrm{MCP}_{514}$ and the evidence that $\mathrm{CheW}$ deficiency does not affect the polar localization of $\mathrm{MCP}_{514}$, it is most likely that $\mathrm{MCP}_{514}$ is localized in the cell poles via interacting with other MCPs. Results from E. coli MCPs showed that the hairpin subdomain of MCP is a coiled-coil of two antiparallel helices with a 'U-turn' and two hairpin subdomains form a supercoiled four-helical bundle, which makes MCP form homodimeric molecules [50]. The dimers of different MCPs can form mixed trimers of dimers via the interactions between their highly conserved helical bundle, and several residues play key roles in the formation of trimer (Figure S1) [51-53]. 


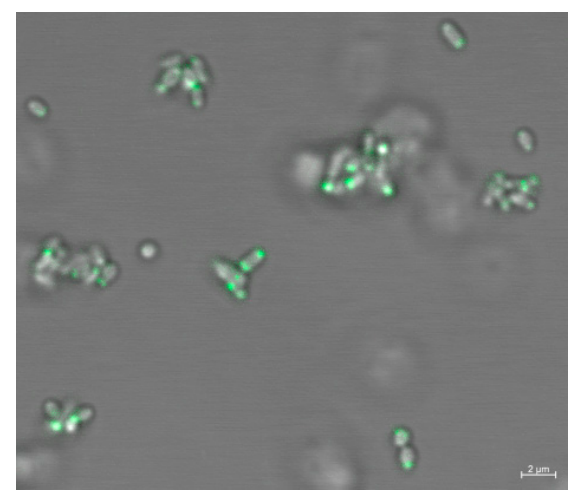

Figure 6. Cellular localization of $\mathrm{MCP}_{514}$ in $\mathrm{CheW}$-deficient $A$. fabrum mutant. Plasmid expressing eGFP-MCP $\mathrm{M}_{514}$ fusion protein was introduced into the atu051-che $W_{1}-c h e W_{2}$ triple-deletion mutant $\Delta 514 \Delta w$. Cells were grown to the middle-log phase and observed by using confocal laser-scanning microscopy.

To determine if the hairpin subdomain of $\mathrm{MCP}_{514}$ affects the cellular localization of $\mathrm{MCP}_{514}$, key residue Phe328 in the hairpin subdomain was changed to Ala, Pro or Trp. These three single-residue-substituted $\mathrm{MCP}_{514}$ variants were fused to eGFP, respectively. Fluorescence observation showed that the substitution of Phe328 for Pro causes the $\mathrm{MCP}_{514}$ diffusion in the cytoplasm (Figure 7C), whereas the replacement of Phe328 by Ala or Trp does not affect the polar location of $\mathrm{MCP}_{514}$ (Figure 7A,B). Proline is a constraint on the formation of helix. Replacement of Phe328 by Pro will destroy the helical structure of the hairpin subdomain. These results demonstrated that the helical structure of the hairpin subdomain is required for the cellular localization of $\mathrm{MCP}_{514}$.
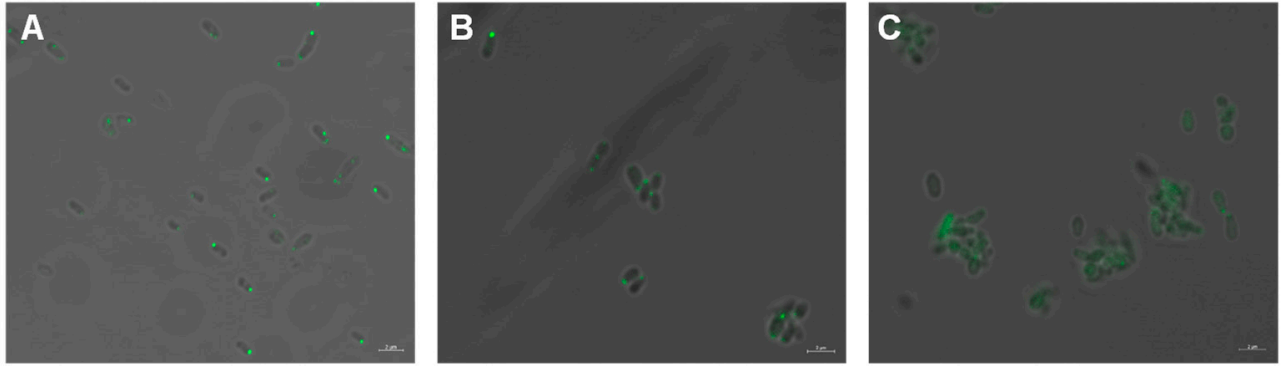

Figure 7. Effects of the substitution of key residue Phe328 on the cellular localization of $\mathrm{MCP}_{514}$. Key residue Phe328 in the hairpin subdomain of $\mathrm{MCP}_{514}$ was replaced by Ala, Pro or Trp to generate three $\mathrm{MCP}_{514}$ variants, $\mathrm{MCP}_{514}{ }^{\mathrm{F} 328 \mathrm{~A}}(\mathbf{A}), \mathrm{MCP}_{514}{ }^{\mathrm{F} 328 \mathrm{~W}}(\mathbf{B})$ and $\mathrm{MCP}_{514}{ }^{\mathrm{F} 328 \mathrm{P}}(\mathrm{C})$. Three $\mathrm{MCP}_{514}$ variants were fused to eGFP and expressed as the eGFP-MCP 514 variant in the $\mathrm{MCP}_{514}$-deficient mutant $\Delta 514$, respectively. A. fabrum mutant $\Delta 514$ cells expressing these eGFP-MCP ${ }_{514}$ variant fusion proteins were grown to the middle-log phase and observed by using confocal laser-scanning microscopy.

\subsection{Two Key Residues of Hairpin Subdomain Play a Key Role in Maintaining the Chemotactic} Function of $M C P_{514}$

The cellular localization of $\mathrm{MCP}_{514}$ is dependent on the hairpin subdomain, which is involved in the interactions between different MCPs, as well as the interactions with the CheA and CheW [54]. The chemotactic signal is collaboratively transduced by the mixed MCP teams, and all signals from different MCPs will converge to CheA [51]. It is reasonable that residues involving in the interaction between MCPs may affect the chemotactic function of $\mathrm{MCP}_{514}$.

To further determine the key residues of $\mathrm{MCP}_{514}$ that are involved in the trimer contact, we aligned the sequence of $\mathrm{MCP}_{514}$ with the sequences of Tsr and Tar from E. coli [55] and chose Phe328, Asn336, Glu340, Arg343 and Val353 of $\mathrm{MCP}_{514}$ as the target residues of the 
site-directed mutation (Figure S2). Five residues were respectively replaced by alanine to generate five single residue-substituted $\mathrm{MCP}_{514}$ variants. These $\mathrm{MCP}_{514}$ variants were expressed in the $\mathrm{MCP}_{514}$-deficient mutant $(\Delta 514)$ by the introduction of the $\mathrm{MCP}_{514}$ variantexpressing plasmid, respectively. Colonies of the $\mathrm{MCP}_{514}$-deficient mutant expressing various $\mathrm{MCP}_{514}$ variants are shown in Figure $8 \mathrm{~A}$. The diameters of these tested strain colonies were used to quantify the effects of various $\mathrm{MCP}_{514}$ variants on the chemotactic response of A. fabrum [43]. As shown in Figure 8, two single residue-substituted $\mathrm{MCP}_{514}$ variants, $\mathrm{MCP}_{514}{ }^{\mathrm{N} 336 \mathrm{~A}}$ and $\mathrm{MCP}_{514}{ }^{\mathrm{V} 353 \mathrm{~A}}$, are unable to restore the chemotactic response of the $\mathrm{MCP}_{514}$-deficient mutant to the level of the wildtype, demonstrating that residues Asn336 and Val353 play a key role in maintaining the chemotactic function of $\mathrm{MCP}_{514}$.
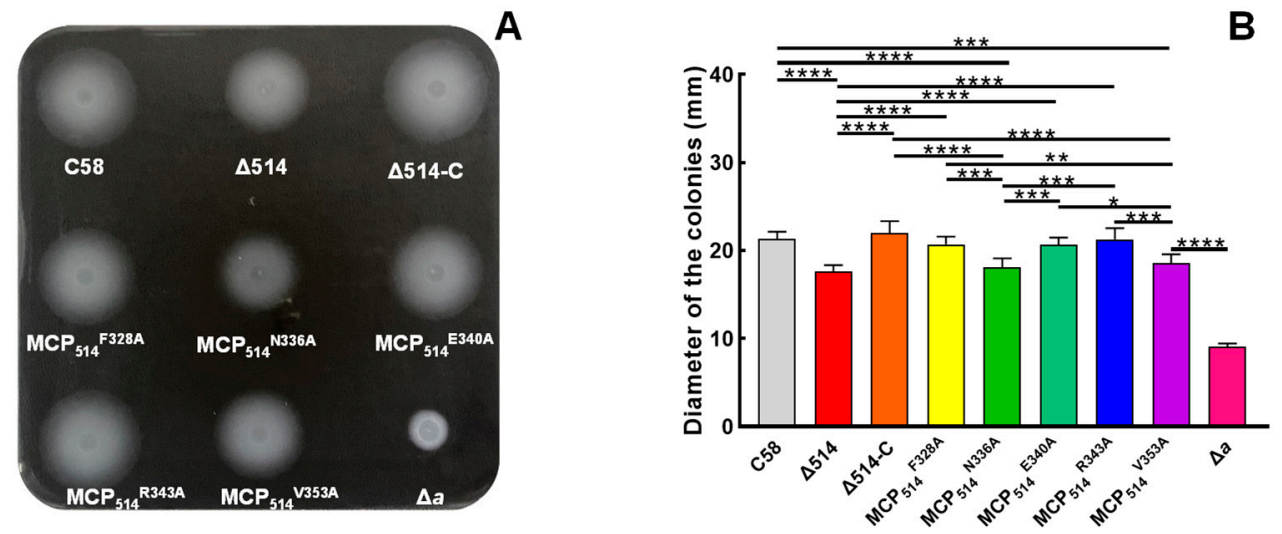

Figure 8. Effects of $\mathrm{MCP}_{514}$ variants on the chemotactic response of $A$. fabrum. The test procedure was the same as described in Figure 3. (A) Typical colonies of these tested A. fabrum strains. (B) The swim-ring diameters of these tested A. fabrum strains on the swim plate. The data represent the means \pm SDs from five independent experiments in triplicate. The bars paired with "**, “***", “***” and "*****" marks represent that they are different in a statistical manner at $p<0.05,0.01,0.001$ and 0.0001, respectively, via the one-way ANOVA, followed by Tukey test. C58, A. fabrum wildtype C58 strain; $\triangle 514, \mathrm{MCP}_{514}$ deficient mutant; $\Delta 514-\mathrm{C}, \Delta 514$ mutant complemented with native $\mathrm{MCP}_{514} ; \mathrm{MCP}_{514}{ }^{\mathrm{F} 328 \mathrm{~A}}, \mathrm{MCP}_{514}{ }^{\mathrm{N} 336 \mathrm{~A}}, \mathrm{MCP}_{514}{ }^{\mathrm{E} 340 \mathrm{~A}}$, $\mathrm{MCP}_{514}{ }^{\mathrm{R} 343 \mathrm{~A}}$ and $\mathrm{MCP}_{514}{ }^{\mathrm{V} 353 \mathrm{~A}}$ represent $\triangle 514$ mutant complemented with the corresponding single residue-substituted $\mathrm{MCP}_{514}$ variants, respectively; $\Delta a$, CheA deficient mutant.

\section{Discussion}

In natural environments, A. fabrum is usually distributed around the rhizosphere of a plant [24]. Chemotaxis is the important initial step for A. fabrum to infect the plant host [56]. Only when A. fabrum correctly recognizes and responds to the chemical signals released by the plant host can it contact the host plant, infect the host and start the tumorigenic processes [27,57-59]. MCPs are the first components of the chemotaxis system. The recognition of chemicals by these proteins is the initial stage of chemotaxis signaling transduction. Adaptive modification of the conserved glutamate domain of the MCP signal domain ensures that they are highly sensitive to different concentrations of chemoeffectors [60]. Although A. fabrum C58 contains $20 \mathrm{MCP}$-encoding genes, only one MCP-encoding gene (atu0514) is in the che operon [12]. It is rational that the $\mathrm{MCP}_{514}$ encoded by the atu0514 gene may play a unique role in the signaling transduction of chemotaxis.

Our results show that $\mathrm{MCP}_{514}$ deficiency significantly affects not only the overall chemotactic response of A. fabrum to nutrient substances (Figure 3 ) but also the chemotaxis toward four various types of chemicals (Figure 4). The ligand binding domain (LBD) of $\mathrm{MCP}_{514}$ is predicted to be a protoglobin, which cannot bind these four tested types of chemicals (Figure 1B). MCPs with different LBDs can form mixed trimers of dimers, and thousands of MCPs form a receptor cluster. The receptor cluster comprised of MCPs with different detection specificities collaboratively transduces the chemotactic signal in a team signaling model [51]. The effects of $\mathrm{MCP}_{514}$ deficiency on the chemotaxis of A. fabrum toward four various types of chemicals demonstrate that $\mathrm{MCP}_{514}$ is a very important 
member of the chemoreceptor signaling team, and the absence of $\mathrm{MCP}_{514}$ will affect the signaling efficiency of the whole chemoreceptor signaling team, explicating the reason of the atu0514 gene locating the che operon.

Based on the sequenced genomes, $43 \%$ of archaeal and $14 \%$ of bacterial MCPs lack a transmembrane (TM) region. These TM-lacking MCPs are classified as cytoplasmic chemoreceptors. Unlike the transmembrane chemoreceptors, which are mainly located at the pole of the cell, cytoplasmic MCPs adopt more exotic locations [22]. Some cytoplasmic chemoreceptors are polarized at one end of the cell, such as, the HemAt of B. subtilis and the IcpA of $S$. meliloti $[21,61]$; other cytoplasmic chemoreceptors have both polar and diffuse states, for example, the AerC of $A$. brasilense was diffused in cytoplasm under an oxygen-rich environment but located in the cell polar under symbiotic nitrogen-fixing state, which helps cells adapt to hypoxic environments [19]. There are also some bacteria whose cytoplasmic chemoreceptors formed clusters in the cytoplasm, for example, the TlpC and TlpT of R. sphaeroides are located in the center of the cell by forming cytoplasmic clusters [62]. It is believed that the subcellular localization and distribution of the cytoplasmic chemoreceptor arrays are associated with the life cycle of bacteria [22]. Our results show that $\mathrm{MCP}_{514}$ localizes cell poles. Although both $\mathrm{CheW}_{1}$ and $\mathrm{CheW}_{2}$ interact with $\mathrm{MCP}_{514}$, respectively, (Figure 5), the cellular localization of $\mathrm{MCP}_{514}$ is independent of CheW (Figure 6), which is consistent with the previous results obtained from E. coli, in which trimers of homodimers of MCPs form clusters of MCPs and in turn recruit CheA/CheW to assemble MCP-CheW-CheA ternary complexes [52,54]. In combination with the previous studies on other cytoplasmic MCPs [22,62], our results could support that this TM-lacking chemoreceptor, $\mathrm{MCP}_{514}$, localizes the cell poles through interacting with other transmembrane chemoreceptors, although the experimental evidence may be required to demonstrate the interaction of $\mathrm{MCP}_{514}$ with other MCPs.

According to the previous studies on Tsr and Tar of E. coli, the hairpin (HP) subdomain of MCP is not only the region forming homodimeric MCP but also the contacting sites for the formation of mixed trimers as well as the assembly of MCP-CheW-CheA ternary complexes $[51,55]$. Five conserved amino acid residues in the two antiparallel helices of $E$. coli Tsr (Phe373, Asn381, Glu385, Arg388 and Val353) are important for the cluster formation and function of MCP [51]. Hydrophobic interactions between the helices contribute to the main trimer packing forces [55]. Five corresponding residues of $\mathrm{MCP}_{514}$ conducted the single residue of the respective substitution. Phe328 of $\mathrm{MCP}_{514}$ is in the key site of the helical structure of the HP subdomain. The replacement of Phe328 by the helix destroyer, proline, results in $\mathrm{MCP}_{514}$ diffusing in the cytoplasm. Replacement of Phe328 by alanine does not affect both the cellular location and chemotactic function of $\mathrm{MCP}_{514}$. These results demonstrate that Phe328 is not the direct determinant to the chemotactic function of $\mathrm{MCP}_{514}$, but indirectly affects $\mathrm{MCP}_{514}$ function through stabilizing the helical structure. Amongst the five tested $\mathrm{MCP}_{514}$ variants, three variants have the full function of the wildtype, which is slightly different from the results of E. coli Tsr [51].

\section{Conclusions}

$\mathrm{MCP}_{514}$ is localized at cell poles, although it lacks a transmembrane region. The cellular localization of $\mathrm{MCP}_{514}$ is independent of the assembly of MCP-CheW-CheA ternary complex but dependent on the interaction with other MCPs through the hairpin (HP) subdomain. Compared with other $\mathrm{MCPs}, \mathrm{MCP}_{514}$ plays a superior role in maintaining the signaling efficiency of the whole chemoreceptor signaling team. The helical structure of the hairpin subdomain is the prerequisite of $\mathrm{MCP}_{514}$ cellular localization and functioning. The molecular mechanism of $\mathrm{MCP}_{514}$ interacting with other MCPs and functioning in the chemotaxis signaling is similar to that of E. coli MCPs, although the roles of some key residues of $\mathrm{MCP}_{514}$ in the transducing signal are slightly different from those of E. coli Tsr. 
Supplementary Materials: The following are available online at https: / www.mdpi.com/article/ 10.3390/microorganisms9091923/s1, Figure S1: Construction procedure, screening and verification of atu0514-deficient mutants. Figure S2: Sequence alignment of three A. fabrum MCPs and two $E$. coli MCPs. Table S1: Bacterial strains and plasmids used in this study. Table S2: Primers used in this study

Author Contributions: Conceptualization, J.Y. and M.G. (Minliang Guo); data curation, J.Y. and Q.Z.; formal analysis, J.Y., M.G. (Miaomiao Gao), Q.Z., H.W., N.X. and M.G. (Minliang Guo); funding acquisition, M.G. (Minliang Guo); investigation, J.Y., M.G. (Miaomiao Gao) and Q.Z.; methodology, J.Y., H.W. and N.X.; project administration, M.G. (Minliang Guo); supervision, M.G. (Minliang Guo); writing — original draft, J.Y.; writing — review and editing, M.G. (Minliang Guo). All authors have read and agreed to the published version of the manuscript.

Funding: This work was funded by the National Natural Science Foundation of China (Grant No. 31870118, 21808196, 31170073).

Institutional Review Board Statement: Not applicable.

Informed Consent Statement: Not applicable.

Data Availability Statement: The data that support the findings of this study are available from the corresponding author upon reasonable request.

Acknowledgments: We thank Yan Lu (the testing and analysis center of Yangzhou University) for help with the confocal laser microscopy observation.

Conflicts of Interest: The authors declare no conflict of interest.

\section{References}

1. Dogra, G.; Purschke, F.G.; Wagner, V.; Haslbeck, M.; Kriehuber, T.; Hughes, J.G.; Van Tassell, M.L.; Gilbert, C.; Niemeyer, M.; Ray, W.K.; et al. Sinorhizobium meliloti CheA complexed with CheS exhibits enhanced binding to CheY1, resulting in accelerated CheY1 dephosphorylation. J. Bacteriol. 2012, 194, 1075-1087. [CrossRef]

2. Sourjik, V.; Wingreen, N.S. Responding to chemical gradients: Bacterial chemotaxis. Curr. Opin. Cell Biol. 2012, $24,262-268$. [CrossRef] [PubMed]

3. Parkinson, J.S.; Hazelbauer, G.L.; Falke, J.J. Signaling and sensory adaptation in Escherichia coli chemoreceptors: 2015 update. Trends Microbiol. 2015, 23, 257-266. [CrossRef] [PubMed]

4. Hazelbauer, G.L.; Falke, J.J.; Parkinson, J.S. Bacterial chemoreceptors: High-performance signaling in networked arrays. Trends Biochem. Sci. 2008, 33, 9-19. [CrossRef] [PubMed]

5. Sourjik, V. Receptor clustering and signal processing in E. coli chemotaxis. Trends Microbiol. 2004, 12, 569-576. [CrossRef] [PubMed]

6. Wadhams, G.; Martin, A.C.; Porter, S.; Maddock, J.; Mantotta, J.; King, H.; Armitage, J. TlpC, a novel chemotaxis protein in Rhodobacter sphaeroides, localizes to a discrete region in the cytoplasm. Mol. Microbiol. 2003, 46, 1211-1221. [CrossRef] [PubMed]

7. Bi, S.; Lai, L. Bacterial chemoreceptors and chemoeffectors. Cell. Mol. Life Sci. 2015, 72, 691-708. [CrossRef]

8. Karmakar, R. State of the art of bacterial chemotaxis. J. Basic Microbiol. 2021, 61, 366-379. [CrossRef]

9. Ortega, A.; Zhulin, I.; Krell, T. Sensory repertoire of bacterial chemoreceptors. Microbiol. Mol. Biol. Rev. 2017, 81, e00033-17. [CrossRef]

10. Sampedro, I.; Parales, R.E.; Krell, T.; Hill, J.E. Pseudomonas chemotaxis. FEMS Microbiol. Rev. 2015, 39, 17-46. [CrossRef]

11. Gavira, J.A.; Gumerov, V.M.; Rico-Jimenez, M.; Petukh, M.; Upadhyay, A.A.; Ortega, A.; Matilla, M.A.; Zhulin, I.B.; Krell, T. How bacterial chemoreceptors evolve novel ligand specificities. mBio 2020, 11, e03066-19. [CrossRef] [PubMed]

12. Guo, M.; Huang, Z.; Yang, J. Is there any crosstalk between the chemotaxis and virulence induction signaling in Agrobacterium tumefaciens? Biotechnol. Adv. 2017, 35, 505-511. [CrossRef]

13. Adadevoh, J.S.; Triolo, S.; Ramsburg, C.A.; Ford, R.M. Chemotaxis increases the residence time of bacteria in granular media containing distributed contaminant sources. Environ. Sci. Technol. 2016, 50, 181-187. [CrossRef] [PubMed]

14. Ud-Din, A.; Khan, M.F.; Roujeinikova, A. Broad specificity of amino acid chemoreceptor CtaA of Pseudomonas fluorescens is afforded by plasticity of its amphipathic ligand-binding pocket. Mol. Plant Microbe Interact. 2020, 33, 612-623. [CrossRef]

15. Yang, W.; Briegel, A. Diversity of bacterial chemosensory arrays. Trends Microbiol. 2020, 28, 68-80. [CrossRef] [PubMed]

16. Zhulin, I. The superfamily of chemotaxis transducers: From physiology to genomics and back. Adv. Microb. Physiol. 2001, 45, 157-198. [CrossRef]

17. Lacal, J.; Garcia-Fontana, C.; Munoz-Martinez, F.; Ramos, J.L.; Krell, T. Sensing of environmental signals: Classification of chemoreceptors according to the size of their ligand binding regions. Environ. Microbiol. 2010, 12, 2873-2884. [CrossRef]

18. Schultz, J.; Milpetz, F.; Bork, P.; Ponting, C. SMART, a simple modular architecture research tool: Identification of signaling domains. Proc. Natl. Acad. Sci. USA 1998, 95, 5857-5864. [CrossRef] 
19. Xie, Z.; Ulrich, L.E.; Zhulin, I.B.; Alexandre, G. PAS domain containing chemoreceptor couples dynamic changes in metabolism with chemotaxis. Proc. Natl. Acad. Sci. USA 2010, 107, 2235-2240. [CrossRef]

20. Schweinitzer, T.; Mizote, T.; Ishikawa, N.; Dudnik, A.; Inatsu, S.; Schreiber, S.; Suerbaum, S.; Aizawa, S.; Josenhans, C. Functional characterization and mutagenesis of the proposed behavioral sensor TlpD of Helicobacter pylori. J. Bacteriol. 2008, 190, $3244-3255$. [CrossRef] [PubMed]

21. Hou, S.; Larsen, R.; Boudko, D.; Riley, C.; Karatan, E.; Zimmer, M.; Ordal, G.; Alam, M. Myoglobin-like aerotaxis transducers in archaea and bacteria. Nature 2000, 403, 540-544. [CrossRef]

22. Collins, K.D.; Lacal, J.; Ottemann, K.M. Internal sense of direction: Sensing and signaling from cytoplasmic chemoreceptors. Microbiol. Mol. Biol. Rev. 2014, 78, 672-684. [CrossRef]

23. Escobar, M.A.; Dandekar, A.M. Agrobacterium tumefaciens as an agent of disease. Trends Plant Sci. 2003, 8, 380-386. [CrossRef]

24. Pitzschke, A.; Hirt, H. New insights into an old story: Agrobacterium-induced tumour formation in plants by plant transformation. EMBO J. 2010, 29, 1021-1032. [CrossRef]

25. Guo, M.; Bian, X.; Wu, X.; Wu, M. Agrobacterium-mediated genetic transformation: History and progress. In Genetic Transformation; Alvarez, M., Ed.; InTech: Rijeka, Croatia, 2011.

26. Kado, C.I. Historical account on gaining insights on the mechanism of crown gall tumorigenesis induced by Agrobacterium tumefaciens. Front. Microbiol. 2014, 5, 340. [CrossRef]

27. Yuan, Z.C.; Williams, M. A really useful pathogen, Agrobacterium tumefaciens. Plant Cell 2012, 24, tpc.112.tt1012. [CrossRef] [PubMed]

28. Hawes, M.; Smith, L. Requirement for chemotaxis in pathogenicity of Agrobacterium tumefaciens on roots of soil-grown pea plants. J. Bacteriol. 1989, 171, 5668-5671. [CrossRef] [PubMed]

29. Ashby, A.; Watson, M.; Loake, G.; Shaw, C. Ti plasmid-specified chemotaxis of Agrobacterium tumefaciens C58C1 toward virinducing phenolic compounds and soluble factors from monocotyledonous and dicotyledonous plants. J. Bacteriol. 1988, 170, 4181-4187. [CrossRef] [PubMed]

30. Loake, G.; Ashby, A.; Shaw, C. Attraction of Agrobacterium tumefaciens C58C1 towards sugars involves a highly sensitive chemotaxis system. J. Gen. Microbiol. 1988, 134, 1427-1432. [CrossRef]

31. Parke, D.; Ornston, L.; Nester, E. Chemotaxis to plant phenolic inducers of virulence genes is constitutively expressed in the absence of the Ti plasmid in Agrobacterium tumefaciens. J. Bacteriol. 1987, 169, 5336-5338. [CrossRef]

32. Winans, S. Two-way chemical signaling in Agrobacterium-plant interactions. Microbiol. Rev. 1992, 56, 12-31. [CrossRef] [PubMed]

33. Wood, D.W.; Setubal, J.C.; Kaul, R.; Monks, D.E.; Kitajima, J.P.; Okura, V.K.; Zhou, Y.; Chen, L.; Wood, G.E.; Almeida, N.F., Jr.; et al. The genome of the natural genetic engineer Agrobacterium tumefaciens C58. Science 2001, 294, 2317-2323. [CrossRef] [PubMed]

34. Goodner, B.; Hinkle, G.; Gattung, S.; Miller, N.; Blanchard, M.; Qurollo, B.; Goldman, B.S.; Cao, Y.; Askenazi, M.; Halling, C.; et al. Genome sequence of the plant pathogen and biotechnology agent Agrobacterium tumefaciens C58. Science 2001, 294, $2323-2328$. [CrossRef]

35. Sambrock, J.; Russel, D. Molecular Cloning: A Laboratory Manual, 3rd ed.; Cold Spring Harbor Laboratory: Cold Spring Harbor, NY, USA, 2001.

36. Cangelosi, G.A.; Best, E.A.; Martinetti, G.; Nester, E.W. Genetic analysis of Agrobacterium. Methods Enzymol. 1991, $204,384-397$. [CrossRef] [PubMed]

37. Gelvin, S.B. Agrobacterium virulence gene induction. Methods Mol. Biol. 2006, 343, 77-84. [CrossRef]

38. Guo, M.; Hou, Q.; Hew, C.L.; Pan, S.Q. Agrobacterium VirD2-binding protein is involved in tumorigenesis and redundantly encoded in conjugative transfer gene clusters. Mol. Plant Microbe Interact. 2007, 20, 1201-1212. [CrossRef]

39. Guo, M.L.; Zhu, Q.; Gao, D.K. Development and optimization of method for generating unmarked A. tumefaciens mutants. Prog. Biochem. Biophys. 2009, 36, 556-565. [CrossRef]

40. Huang, Z.; Zhou, Q.; Sun, P.; Yang, J.; Guo, M. Two Agrobacterium tumefaciens CheW proteins are incorporated into one chemosensory pathway with different efficiencies. Mol. Plant Microbe Interact. 2018, 31, 460-470. [CrossRef]

41. Higuchi, R. Using PCR to engineer DNA. In PCR Technology; Palgrave Macmillan: London, UK, 1989; pp. 61-70.

42. Adler, J. A method for measuring chemotaxis and use of the method to determine optimum conditions for chemotaxis by Escherichia coli. Microbiology 1973, 74, 77-91. [CrossRef]

43. Merritt, P.M.; Danhorn, T.; Fuqua, C. Motility and chemotaxis in Agrobacterium tumefaciens surface attachment and biofilm formation. J. Bacteriol. 2007, 189, 8005-8014. [CrossRef]

44. Miller, J. Experiments in Molecular Genetics; Cold Spring Harbor Laboratory: Cold Spring Harbor, NY, USA, 1972 ; Volume 172.

45. Alexander, R.; Zhulin, I. Evolutionary genomics reveals conserved structural determinants of signaling and adaptation in microbial chemoreceptors. Proc. Natl. Acad. Sci. USA 2007, 104, 2885-2890. [CrossRef]

46. Hirokawa, T.; Boon-Chieng, S.; Mitaku, S. SOSUI: Classification and secondary structure prediction system for membrane proteins. Bioinformatics 1998, 14, 378-379. [CrossRef]

47. Juretić, D.; Zoranić, L.; Zucić, D. Basic charge clusters and predictions of membrane protein topology. J. Chem. Inf. Comput. Sci. 2002, 42, 620-632. [CrossRef]

48. Greenfield, D.; McEvoy, A.L.; Shroff, H.; Crooks, G.E.; Wingreen, N.S.; Betzig, E.; Liphardt, J. Self-organization of the Escherichia coli chemotaxis network imaged with super-resolution light microscopy. PLoS Biol. 2009, 7, e1000137. [CrossRef] [PubMed] 
49. Zhou, Q. Functional Identification of Methyl Accepting Chemotaxis Protein Encoded by Gene atu0514 Located in the Chemotaxis Operon of Agrobacterium tumefaciens. Master's Thesis, Yangzhou University, Yangzhou, China, 2020.

50. Kim, K.K.; Yokota, H.; Sangjin, K. Four-helical-bundle structure of the cytoplasmic domain of a serine chemotaxis receptor. Nature 1999, 400, 787-792. [CrossRef] [PubMed]

51. Ames, P.; Studdert, C.; Reiser, R.; Parkinson, J. Collaborative signaling by mixed chemoreceptor teams in Escherichia coli. Proc. Natl. Acad. Sci. USA 2002, 99, 7060-7065. [CrossRef] [PubMed]

52. Studdert, C.; Parkinson, J. Crosslinking snapshots of bacterial chemoreceptor squads. Proc. Natl. Acad. Sci. USA 2004, 101, 2117-2122. [CrossRef] [PubMed]

53. Studdert, C.A.; Parkinson, J.S. Insights into the organization and dynamics of bacterial chemoreceptor clusters through in vivo crosslinking studies. Proc. Natl. Acad. Sci. USA 2005, 102, 15623-15628. [CrossRef]

54. Li, M.; Khursigara, C.M.; Subramaniam, S.; Hazelbauer, G.L. Chemotaxis kinase CheA is activated by three neighbouring chemoreceptor dimers as effectively as by receptor clusters. Mol. Microbiol. 2011, 79, 677-685. [CrossRef]

55. Gosink, K.K.; Zhao, Y.; Parkinson, J.S. Mutational analysis of N381, a key trimer contact residue in Tsr, the Escherichia coli serine chemoreceptor. J. Bacteriol. 2011, 193, 6452-6460. [CrossRef]

56. Wright, E.; Deakin, W.; Shaw, C. A chemotaxis cluster from Agrobacterium tumefaciens. Gene 1998, 220, 83-89. [CrossRef]

57. McCullen, C.A.; Binns, A.N. Agrobacterium tumefaciens and plant cell interactions and activities required for interkingdom macromolecular transfer. Annu. Rev. Cell Dev. Biol. 2006, 22, 101-127. [CrossRef]

58. Gelvin, S.B. Traversing the cell: Agrobacterium T-DNA's journey to the host genome. Front. Plant Sci. 2012, 3, 52. [CrossRef] [PubMed]

59. Pitzschke, A. Agrobacterium infection and plant defense-Transformation success hangs by a thread. Front. Plant Sci. 2013, 4, 519. [CrossRef] [PubMed]

60. Szurmant, H.; Ordal, G.W. Diversity in chemotaxis mechanisms among the bacteria and archaea. Microbiol. Mol. Biol. Rev. 2004, 68, 301-319. [CrossRef] [PubMed]

61. Meier, V.M.; Scharf, B.E. Cellular localization of predicted transmembrane and soluble chemoreceptors in Sinorhizobium meliloti. J. Bacteriol. 2009, 191, 5724-5733. [CrossRef]

62. Briegel, A.; Ladinsky, M.S.; Oikonomou, C.; Jones, C.W.; Harris, M.J.; Fowler, D.J.; Chang, Y.W.; Thompson, L.K.; Armitage, J.P.; Jensen, G.J. Structure of bacterial cytoplasmic chemoreceptor arrays and implications for chemotactic signaling. Elife 2014, 3, e02151. [CrossRef] 